TAPROBANICA, ISSN 1800-427X. April, 2013. Vol. 05, No. 01: pp. 44-49, 1 pl. (C) Taprobanica Private Limited, 146, Kendalanda, Homagama, Sri Lanka. www.taprobanica.org

\title{
ETHOGRAM OF COURTSHIP AND MATING BEHAVIOUR OF Sitana cf. ponticeriana (REPTILIA: DRACONINAE: AGAMIDAE) IN INDIA
}

\author{
Pratyush Patankar ${ }^{1}$, Isha Desai ${ }^{2}$, Jignesh N. Trivedi ${ }^{1}$ and Suresh Balakrishnan ${ }^{1,3}$
}

\footnotetext{
${ }^{1}$ Department of Zoology, The M. S. University of Baroda, Vadodara 390 002, Gujarat, India.

${ }^{2}$ Department of Bioscience, N. V. Patel college of pure \& applied sciences, Anand 388 120, Gujarat, India. E-mail: suved9@ hotmail.com ${ }^{3}$
}

\begin{abstract}
The current study describes and interprets the courtship behaviour exhibited by Sitana cf. ponticeriana. An ethogram comprised of 20 behavioural acts was compiled. Though complex communications were lacking in S. cf. ponticeriana, other acts were by and large similar (and perhaps evolutionarily homologous) to other agamids. The courtship behaviour was divided into three distinct patterns - orientation, persuasion and copulation. Gular flap extensions by the males of $S$. cf. ponticeriana was a peculiar display but not unique to this species. Head bobbing, which is a common feature to many agamids, was rare and functioned to enhance the visual acuity rather than to serve as a social signal. Neck grip was also a very short event performed rapidly by the male to subdue the female. Rest events of the courtship were more or less similar to other types of lizards. Tail twitching and tail twisting seemed to express high levels of arousal rather than ritualized social signals.
\end{abstract}

Key words: fan-throated lizard, orientation, persuasion, copulation, behaviour type, ethology.

\section{Introduction}

Studies on the courtship behaviour or social behaviour of lizards are not very common and many of them are in fact carried out as part of larger ecological studies. A few ethograms and several other studies on the courtship behaviour have been published for lizards, but these are mainly focused either on iguanids (Cooper, 1979; Greenberg, 1977a,b; Jenssen, 1975; Jenssen \& Feely, 1991) or on scincids (Cooper \& Vitt, 1987a; Done \& Heatwole, 1977;
Langkilde et al., 2003; Torr \& Shine, 1994). Studies describing the sequential events in courtship and mating behaviour in agamids are rare (Brattstrom, 1971; Carpenter et al., 1970; Pandav et al., 2007). Jenssen (1975) stated that display behaviour of lizards tend to be stereotyped at the species level in most of the cases or even at the level of population, and this stereotypy enables compilation of a list (ethogram) of display behaviour for a species, covering the whole range of behavioural acts. 
Courtship displays in lizards may be aided by auditory, chemical or visual cues (Carpenter \& Ferguson, 1977). Nocturnal lizards like geckos rely mainly on auditory/vocal cues (Frankenberg, 1982) or chemical cues (Cooper \& Vitt, 1987b), while agamids, being primarily diurnal, communicate through visual signals that are often delivered in a predictable sequence, together with characteristic postures and changes in body colouration (Carpenter \& Ferguson, 1977). Interestingly, agamid lizards exhibit strikingly colourful visual displays. Along with the genera Calotes (Pandav et al., 2007) and Psammophilus (Radder et al., 2006) from the Indian context, genus Sitana also exhibits colourful courtship acts that are well noticed in the field.

The genus Sitana has long been considered as monotypic (Manamendra-Arachchi \& Liyanage, 1994), with Sitana ponticeriana Cuvier, 1829 as the only recognized species. Although additional species, namely Sitana minor (Gunther, 1864) and Sitana deccanensis (Jerdon, 1870), had already been described, Boulenger (1885) merged them into one species that subsequently led to the $S$. ponticeriana complex through its distribution range. To resolve these taxonomic difficulties within Sitana, extensive pholidotic studies on $S$. ponticeriana complex were conducted by Schleich et al. (1998a,b) and their findings led to the description of two new species separated from S. ponticeriana complex, namely Sitana fusca (Schleich \& Kästle, 1998c) and Sitana sivalensis (Schleich et al., 1998a; Schleich \& Kästle, 1998b). Conducting further studies on the genus Sitana and based upon the species descriptions by Schleich et al. (1998a,b,c), Anders \& Kästle (2002) further described a new species Sitana schleichi from west Nepal. All these species have been described based upon the detailed pholidosis of the external characters, indicating the inadequate use of scale morphology and count as an essential tool for the intrageneric taxonomy. The use of name $S$. cf. ponticeriana in the current study is in lieu of lack of detailed pholidotic studies on Sitana from the western part of India. Moreover, since Schleich et al., (1998a) also suggest that only scale morphology and count cannot reliably describe new species within a genus, the communication system may serve as a significant cue for divergence within a genus. Courtship signals and mating behaviour play an essential role as reproductive isolation mechanism, and hence these courtship acts could serve as useful tools to deal with taxonomy of genus Sitana (Schleich et al., 1998a). With this in mind, the current study was planned wherein the sequential events of courtship and mating behavior of $S$. cf. ponticeriana from its natural habitat is carefully observed and presented.

\section{Material and Methods}

Study Area: The present study was undertaken in a scrubland of Vadodara district spreading over an area of $7 \mathrm{~km}^{2}$, located towards west of Vadodara city at a distance of $16 \mathrm{~km}\left(22^{\circ} 18^{\prime}-\right.$ $22^{\circ} 18^{\prime} \mathrm{N}, 73^{\circ} 06^{\prime}-73^{\circ} 21^{\prime} \mathrm{E}$ ) and harbours a healthy population of Sitana cf. ponticeriana.

Data collection: The courtship behaviour of Sitana cf. ponticeriana was studied in the wild in 12 encounters. Observations were recorded from mid April to mid June with the commencement of the breeding season of $S$. cf. ponticeriana, when males attained their breeding colouration and started with the fanning behaviour until the final act of copulation was observed. Since lizards became highly motile during the breeding season and males with their fanning displays were conspicuous, spotting individuals was not difficult. We observed mating pairs from a distance of approximately $2 \mathrm{~m}$, remaining still as much as possible (except for noting the observations) to avoid disturbing their activity. The courtship behaviour was mainly encountered between $0830 \mathrm{~h}$ and $1230 \mathrm{~h}$ as well as $1600 \mathrm{~h}$ and $1830 \mathrm{~h}$. Observers wrote field notes and tried to capture the sequence of events using a digital camera 'Olympus C770' without disturbing the lizards. The terminologies used for behaviour are mostly after Carpenter \& Ferguson (1977).

\section{Results}

With commencement of the breeding season males of Sitana cf. ponticeriana attained their breeding colouration. In the present study we observed that a purplish blue colour developed on the neck portion of the male and a midventral blue coloured streak developed along the edge of the gular flap, starting from the mental scale reaching almost half or more of the length of the gular flap; the entire gular flap developed into a cream white to pale yellow colour that might intensify a little in few 
individuals. The observed colouration thus contradicts with the one mentioned in the literature (Daniel, 2002; Das, 2008). Females as a general rule remained drab and dull; the only phenotypic change observed was the distension of the abdomen as they become gravid. The sexually matured males measured $42.2 \pm 0.02$ $\mathrm{mm}$ (SVL) and weighed $2.48 \pm 0.24 \mathrm{~g}$, while the SVL of gravid females was $4.64 \pm 0.1 \mathrm{~mm}$ and weighed $2.65 \pm 0.08 \mathrm{~g}$. The courtship behaviour was observed with an uninterrupted gap between the stated time intervals. Based upon these observations, we present an ethogram giving a complete sequence of the events. A total of 20 types of behaviour associated with the courtship were recorded.

Behaviour types: Aggression, aggressive and dominating actions performed by male; Amplexus, male mounting over the female with fore leg holding female's trunk and hind leg holding female's tail base; Chase, rapid pursuit of one male by another and the submissive male retreats; Circling, male approaches female with lateral orientation facing off the female in a circular or semicircular path; Combat, a sporadic fight followed by a chase between the two approaching males near the female; Copulation, intromission of hemipenis into the vent of the female; stationary for 4-8 $\mathrm{s}$ and withdrawal of the hemipenis; Copulatory plug, both male and female held up in a plug for 3-5 $\mathrm{s}$ during copulation while facing in opposite direction; Dewlap extensions/fanning, rapid extension of the gular flap by the male due to the muscular movements of the hyoid apparatus; Flee, rapid retreat of the submissive male when chased by the dominant male, as well as post-mating retreat by the copulating male; Follow, following of the female by the male; Fore-leg push-up, rapid raising and lowering of the body by the male only on the fore legs; Grip release, male releases his grip on the female; Neck bite, male bites the skin on the neck of the female with its jaws causing no injury and releases immediately, Push-up, rapid raising and lowering of the entire body, chiefly the anterior region on all the four legs; Stand high, a stiff pose by the male on the ground by raising the body high on the forelegs; Stationary, no body movements for 3-4 s during the mounting; Straddle, male holds the female by embracing with the limbs and climbs onto the back of the female;
Submission, final acceptance of the female for the mating; Tail twitching, tail lifted at the base, mid portion up and tip directed in the air not touching the substrate; Tail twist, male's tail twisted under the female's tail bringing the cloaca close to that of the female.

These behavioural units account for the majority of the events during the courtship and further can be distinguished into 11 distinct functional units as described below: Circling, as the female signals her acceptance by the courtship stand, the male approaches her by circling; Courtship approach, male's approach towards female with courtship displays i.e. dewlap extensions or fanning; Courtship display, male performs the courtship display by his dewlap extension/fanning, initially from the shrub canopy and later from the ground; Courtship response, female shows an acceptance response by moving to the ground from the shrub; Courtship stand, the female stands rigid and immobile as the courting male approaches her and does not try to flee; Display site selection, males chooses a strategic position on the shrub always higher than the female for the initial display; Female acceptance, female shows her acceptance by moving to the ground from her perch followed by the courtship approach by the male in semicircular path; Grip release, male releases the leg hold on the female and the female is released free. Both the lizards face opposite to each other while in copulation and thereafter the male withdraws the hemipenis; Mounting, the male assumes superior position on the female's dorsum and front leg hold on the female's trunk; Post-mating behaviour, the male moves to a near by shrub after mating and perches on the middle branches of the shrubs, while the female retreats to the base of the shrub where she was perching prior to mating and this is perhaps the site she has selected to lay her clutch; Submissive behaviour, the receptive female shows this behaviour with head down, back arched and cloaca touching the ground with tail up at base. The receptive female shows submissive behaviour in acceptance for mating as the male approaches with circling.

The sequential events of courtship behaviour of Sitana cf. ponticeriana are represented through a flow diagram in Figure 1. The courtship 
behaviour may be divided into three distinct phases, namely orientation, persuasion and copulation.

Orientation: Initially the gravid female is perching on a shrub at an approximate height of $30-40 \mathrm{~cm}$, when she is approached by the male. Usually, a single male was seen approaching a female but in 3 of $12(25 \%)$ field encounters, two approaching males were observed. In these cases, as both the males tried to gain an access to the canopy height, the dominant male chased his competitor from the shrub. This resulted in a very short, sporadic combat between the two on the ground, after which the submissive male fled. The successful male then continued to gain its highest position on the shrub canopy, higher than the female, and began its initial displays through dewlap extensions (32-35 extensions per minute). This initial phase of the courtship lasted for a mean of $4.82 \mathrm{~min}$. Thereafter, the receptive female moves to the ground from the shrub as the courtship response, followed by the male. The male then begins his later part of display through dewlap extensions from the ground along with foreleg pushups and approaches the female by circling movements. This event lasted for a mean of $9.63 \mathrm{~min}$

Persuasion: The receptive female that has already expressed the courtship response by moving to the ground, now takes the courtship stand by remaining immobile towards the approach of the courting male. The male moves towards the receptive female by circling movements getting closer to the female. When the male is at a distance of $20-30 \mathrm{~cm}$ from the female, he makes his first approach through a sudden sprint towards the female, bites her on the neck and moves behind. The neck bite and release of the male subdues the female and she expresses the submissive posture by lowering her head, arching the back and touching the cloaca to the ground by lifting the tail up at the base. These events of the second phase of the courtship lasted for about a mean of $2.14 \mathrm{~min}$. Thereafter the male makes his second approach while the female is still in her submissive posture and mounts the female (approx 0.6 $\min )$.

Copulation: Copulation, although clearly defined, was brief (a mean of $0.8 \mathrm{~min}$ ): the male takes a firm grip hold on the female's back and twists its tail under that of female's tail. The male then brings his cloaca in contact with that of female and this is followed by the intromission of hemipenis and copulation is achieved. The pair remains in this position for 6-9 s and then face opposite to each other locked in copulatory plug. After the copulation, male moves in the opposite direction, loses the contact with the female and moves away. The male moves to a nearby shrub, perches on middle branch and rests while the female retreats to the base of the shrub where she was initially perching; this is perhaps the site she has selected for laying her clutch.

\section{Discussion}

The prime role of an ethogram is to facilitate comparisons among species. With the current dearth of information on agamid lizards, little can be achieved in this regard until data are available for a wider range of lizards. While Pal et al. (2011) have studied the sexual dichromatism in Sitana ponticeriana, an account of its courtship behaviour remains to be taken. Our discussion is therefore necessarily speculative, and based mainly on comparisons with Calotes versicolor (Pandav et al., 2007) and distantly-related lizards in other families. Pandav et al. (2007) mention change in the body colour of $C$. versicolor as an initiating step towards courtship while females of $C$. versicolor also showed a colour change as a sign of acceptance. However, in case of $S$. cf. ponticeriana no such body colour change in either of the sexes was observed during the entire courtship period. The colouration that was attained by the males of $S$. cf. ponticeriana at the commencement of the breeding season remained unaltered throughout, whereas females of this species show no change in their body colour, either before or after the courtship.

Head-bobbing behaviour is well documented in many agamids (Brattstorm, 1971; Pandav et al., 2007; Radder et al., 2006), iguanids (Macedonia \& Clark, 2001; Martins \& Lamont, 1998; Martins et al., 2004; McCann, 1993) and some of the larger scincids (Done \& Heatwole, 1977). If this behaviour does increase visual acuity, then in agamids and iguanids it has perhaps arisen for gaining of better visual information about an intruder in their territory and then over a temporal scale, has developed into the species-specific displays seen today. 
Head-bob behaviour was found to be completely lacking in Sitana cf. ponticeriana, except for an occasional head-nod by the individuals, especially by the males displaying from the ground. This perhaps indicated vigilance for predators. Torr \& Shine (1994) have not documented this behaviour in a species of small skink Lampropholis guichenoti and suggest this as a secondary loss, since small lizards do not tend to defend territories. As territoriality is not well documented in $S$. cf. ponticeriana, this justifies the absence of headbob behaviour in this species.

Rest behaviours during the courtship were almost similar to other agamid lizards (Pandav et al., 2007; Radder et al., 2006). The display act through dewlap extension/fanning by the male of Sitana cf. ponticeriana was the most conspicuous and spectacular event of the entire courtship. Though not unique to the species, this act is not well pronounced in other agamids found in this part of the country. Push-up displays by both the sexes have been reported in Calotes versicolor (Pandav et al., 2007) and Psammophilus dorsalis (Radder et al., 2006); however in case of $S$. cf. ponticeriana, this display was not observed for females. Push-up displays on hind legs have been described for Amphibolurus decresii. This display was also not recorded in the present study as well as in case of Calotes versicolor Pandav et al. (2007).

The current ethogram is limited only to the courtship behaviour of Sitana cf. ponticeriana and behavioural acts exhibited by the species in other events of its life are not covered. A first look at this ethogram of courtship reveals a simple sequence of events, not involving any highly complex communication or visual displays. However, to better understand the visual cues associated with the courtship behavior in this lizard, and to correlate these with those of other species, a wide range of data on phylogenetically closer species is required. That would then help in analyzing the trend of the courtship behavior and the events therein on an evolutionary scale. We expect that our observations will provide a baseline for future studies dealing with the neuroendocrine aspects of courtship behavior in lizards. We hope that these observations may also help resolve the taxonomic intricacies within the genus Sitana.

\section{Literature cited}

Anders, C. and W. Kästle, 2002. Sitana schleichi n. sp., In: Schleich, H. H. \& W. Kästle (eds.). Amphibians and Reptiles of Nepal. A. R. G. Gantner, Verlag K. G., Ruggel: 652-658.

Boulenger, G. A., 1885. Catalogue of the Lizards in the British Museum, second edition - Volume 1, London: xii+436+Pl. I-32.

Brattstrom, B. H., 1971. Social and thermoregulatory behaviour of the bearded dragon Amphibolurus barbatus. Copeia: 487947.

Carpenter, C. C. and G. W. Ferguson, 1977. Variation and evolution of stereotyped behaviour in reptiles. In: Gans, C. and D. W. Tinkle (eds.). Biology of the Reptilia, Ecology and Behaviour, Academic Press, London: 335-457.

Carpenter, C. C., J. A. Badham and B. Kimble, 1970. Behaviour patterns of three species of Amphibolurus (Agamidae). Copeia, 3: 497-505.

Cooper Jr., W. E., 1979. Variability and predictability of courtship in Anolis carolinensis (Reptilia, Lacetilia, Iguanidae). Journal of Herpetology, 13: 233-243.

Cooper Jr., W. E. and L. J. Vitt, 1987a. Deferred agonistic behaviour in a long-lived scincid lizard Eumeces inexpectatus. Oecologia, 73: 321-326.

Cooper Jr., W. E. and L. J. Vitt, 1987b. Ethological isolation, sexual behaviour and pheromones in the Fasciatus species group of the lizard genus Eumeces. Ethology, 75: 328-336.

Daniel, J. C., 2002. The Book of Indian Reptiles and Amphibians. BNHS and Oxford University Press, Mumbai: 238.

Das, I., 2008. A Photographic Guide to Snakes and other Reptiles of India. Om Books International, New Delhi: 81.

Done, B. S. and H. Heatwole, 1977. Social behaviour in some Australian skinks. Copeia, 3: 419-430.

Frankenberg, E., 1982. Vocal behaviour of the Mediterranean house gecko, Hemidactylus turcicus. Copeia, 4: 770-775.

Greenberg, N., 1977a. A neuroethological study of display behaviour in the lizard Anolis carolinensis (Reptilia, Lacertilia, Iguanidae). American Zoologist, 17: 191-201. 
Greenberg, N., 1977b. An ethogram of the blue spiny lizard, Sceloporus cyanogenys (Reptilia, Lacertilia, Iguanidae). Journal of Herpetology, 11: 177-195.

Günther, A., 1864. The Reptiles of British India. The Ray Society, London: 452.

Jensen, T. A., 1975. Display repertoire of a male Phenacosaurus heterodermus (Sauria: Iguanidae). Herpetoligica, 31: 48-55.

Jensen, T. A. and P. C. Feely, 1991. Social behaviour of the male anoline lizard Chamaelinorops barbouri, with a comparison to Anolis. Journal of Herpetology, 25: 454-462.

Jerdon, T. C., 1870. Notes on Indian Herpetology. Proceedings of the Asiatic Society Bengal: 66-85.

Langkilde, T., L. Sciiwarzkopf and R.. Alford, 2003. An ethogram for adult male rainbow skinks, Carlia jarnoldae. Herpetological Journal, 13: $141-148$

Macedonia, J. M. and D. L. Clark, 2001. Headbob display analysis of the Grand Cayman anole, Anolis conspersus. Journal of Herpetology, 35: 300-310.

Manamendra-Arachchi, K. and S. Liyanage, 1994. Conservation of the Agamid lizards of Sri Lanka with illustration of the extant species. Journal of South Asian Natural History, 1 (1): 7796.

Martins, E. P. and J. Lamont, 1998. Estimating ancestral states of communicative display: a comparative study of Cyclura rock iguanas. Animal Behaviour, 55: 1685-1706.

Martins, E. P., A. Labra, M. Halloy and J. T. Thompson, 2004. Large-scale patterns of signal evolution: an interspecific study of Liolaemus lizard and headbob displays. Animal Behaviour, 68: 453-463.

McCann, S., 1993. Contextual signaling and the structure of dyadic encounters in Anolis carolinensis. Animal Behaviour, 46: 657-668.

Pal, A., M. M. Swain and S. Rath, 2011. Reproduction and sexual dichromatism in Sitana ponticeriana (Reptilia: Draconinae: Agamidae). Taprobanica, 3 (1): 31-37.
Pandav, B. N., B. A. Shanbaug, and S. K. Saidapur, 2007. Ethogram of courtship and mating behaviour of garden lizard, Calotes versicolor. Current Science, 93 (8): 1164-1167.

Radder, R. S., S. K. Saidapur, R. Shine and B. A. Shanbaug, 2006. The language of lizards: interpreting the function of visual displays of the Indian rock lizard, Psammophilus dorsalis (Agamidae). Journal of Ethology, 24: 275-283.

Schleich, H. H., W. Kästle and K. B. Sah, 1998a. Description of Sitana sivalensis spec. nov. (Sauria: Agamidae) from South Nepal. In: Schleich, H. H. \& W. Kästle (eds.). Contributions to the Herpetology of South-Asia (Nepal: India). Wuppertal (Veröffentlichungen aus dem Fuhlrott-Museum): 87-100.

Schleich, H. H. and W. Kästle, 1998b. SEM Studies on the morphology of Sitana sivalensis spec. nov. and Sitana ponticeriana Cuvier, 1829. In: Schleich, H. H. \& W. Kästle (eds.). Contributions to the Herpetology of South-Asia (Nepal: India). Wuppertal (Veröffentlichungen aus dem Fuhlrott-Museum): 101-120.

Schleich, H. H. and W. Kästle, 1998c. Sitana fusca spec. nov., a further Species from the Sitana sivalensis Complex. In: Schleich, H. H. and W. Kästle (eds.). Contributions to the Herpetology of South-Asia (Nepal: India). Wuppertal (Veröffentlichungen aus dem Fuhlrott-Museum): 207-226.

Torr, G. A. and R. Shine, 1994. An ethogram for the small scincid lizard Lampropholis guichenoti. Amphibia-Reptilia, 15: 21-34. 


\section{PLATE 6}

Male ふ1 (Dominant)

Initial Displays by Gular Extensions \& Pushups

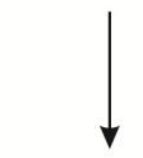

1st Approach
Male ${ }^{ð 2}$ (Recessive)

Initial Displays by Gular Extensions \& Pushups

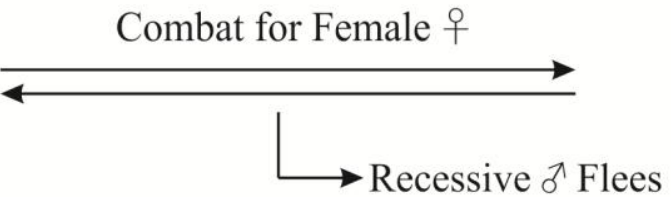

1st Approach

2nd Approach by the Dominant $ぇ$ By Gular Extensions from a shrub canopy by climbing the same shrub and taking a position higher to the 우

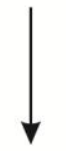

3rd Approach by the Dominant $\precsim$ by Gular Extensions from the ground and by pushups

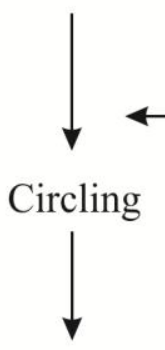

Neck Bite $\&$ Release

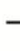

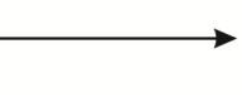

Both $ð$ \& 우 face opposite directions while in copulation plug

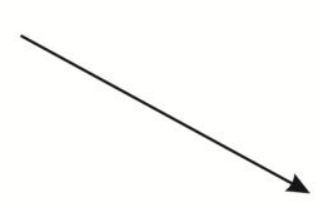

Copulatory Plug Release

Post Mating Push-up

Head bobs ठ

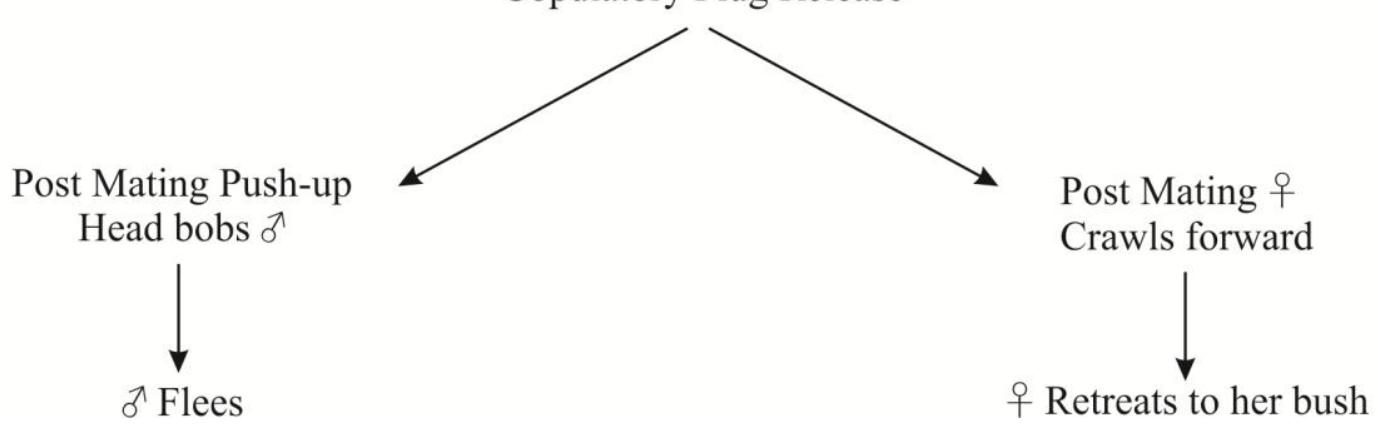

Receptive 우 on a shrub

Receptive ㅇ moves on the ground

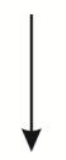

Submission

Figure 1: Summary of sequential events during the courtship and mating behaviour of Sitana cf. ponticeriana 